\title{
A haplotype of polymorphisms in ASE-I, RAI and ERCCI and the effects of tobacco smoking and alcohol consumption on risk of colorectal cancer: a danish prospective case-cohort study
}

\author{
Rikke D Hansen ${ }^{1,2}$, Mette Sørensen ${ }^{2}$, Anne Tjønneland ${ }^{2}$, Kim Overvad ${ }^{3}$, \\ Håkan Wallin ${ }^{1}$, Ole Raaschou-Nielsen ${ }^{2}$ and Ulla Vogel ${ }^{* 1,4}$
}

Address: ${ }^{1}$ National Research Centre for the Working Environment, Lersø Parkalle 105, 2100 Copenhagen, Denmark, ${ }^{2}$ Institute of Cancer Epidemiology, Danish Cancer Society, Strandboulevarden 49, 2100 Copenhagen, Denmark, ${ }^{3}$ Department of Clinical Epidemiology, Aalborg Hospital, Stengade 10, Postbox 561 Aarhus University Hospital, 9000 Aalborg, Denmark and ${ }^{4}$ Department of Science, Systems and Models, University of Roskilde, 4000 Roskilde, Denmark

Email: Rikke D Hansen - RikkeHan@cancer.dk; Mette Sørensen - Mettes@cancer.dk; Anne Tjønneland - Annet@cancer.dk; Kim Overvad - KO@dce.au.dk; Håkan Wallin - HWA@nrcwe.dk; Ole Raaschou-Nielsen - Ole@cancer.dk; Ulla Vogel* - UBV@nrcwe.dk

* Corresponding author

Published: 20 February 2008

BMC Cancer 2008, 8:54 doi:10.1186/147I-2407-8-54

This article is available from: http://www.biomedcentral.com/I47I-2407/8/54

(c) 2008 Hansen et al; licensee BioMed Central Ltd.

This is an Open Access article distributed under the terms of the Creative Commons Attribution License (http://creativecommons.org/licenses/by/2.0), which permits unrestricted use, distribution, and reproduction in any medium, provided the original work is properly cited.
Received: 5 January 2007

Accepted: 20 February 2008

\begin{abstract}
Background: Single nucleotide polymorphisms (SNPs) are the most frequent type of genetic variation in the human genome, and are of interest for the study of susceptibility to and protection from diseases. The haplotype at chromosome 19q13.2-3 encompassing the three SNPs ASE-I G-2IA, RAI IVSI A4364G and $E R C C I$ Asn I I8Asn have been associated with risk of breast cancer and lung cancer. Haplotype carriers are defined as the homozygous carriers of RAI IVSI A4364GA, ERCCI AsnII8Asn ${ }^{\top}$ and ASE-I G-2IAG. We aimed to evaluate whether the three polymorphisms and the haplotype are associated to risk of colorectal cancer, and investigated gene-environment associations between the polymorphisms and the haplotype and smoking status at enrolment, smoking duration, average smoking intensity and alcohol consumption, respectively, in relation to risk of colorectal cancer.
\end{abstract}

Methods: Associations between the three individual polymorphisms, the haplotype and risk of colorectal cancer were examined, as well as gene-environment interaction, in a Danish case-cohort study including 405 cases and a comparison group of 810 persons. Incidence rate ratio (IRR) were estimated by the Cox proportional hazards model stratified according to gender, and two-sided $95 \%$ confidence intervals $(\mathrm{Cl})$ and $p$-values were calculated based on robust estimates of the variance-covariance matrix and Wald's test of the Cox regression parameter.

Results: No consistent associations between the three individual polymorphisms, the haplotype and risk of colorectal cancer were found. No statistically significant interactions between the genotypes and the lifestyle exposures smoking or alcohol consumption were observed.

Conclusion: Our results suggest that the ASE-I G-2IA, RAI IVSI A4364G and ERCCI AsnII8Asn polymorphisms and the previously identified haplotype are not associated with risk of colorectal cancer. We found no evidence of gene-environment interaction between the three polymorphisms and the haplotype and smoking intensity and alcohol consumption, respectively, in relation to the risk of colorectal cancer. 


\section{Background}

SNPs in DNA repair genes have been associated to risk of several types of cancer, reviewed in [1]. Combining of neighbouring SNPs into haplotypes may increase the association with disease. We have previously identified a haplotype at chromosome 19q13.2-3 encompassing three SNPs in the genes ERCC1 (excision repair cross complementary group1), ASE-1 (antisense ERCC1, alias $C D 3 E A P$ ) and RAI (RelA-associated inhibitor, alias $i A S P P$ or $P P P 1 R 13 L$ ), strongly associated with risk of post-menopausal breast cancer [2] and lung cancer [3,4], and a recent Norwegian study has reported a possible association with risk of colorectal cancer among women [5]. Thus, the haplotype seems to be involved in a mechanism affecting various cancer forms. The previously identified haplotype consists of three marker SNPs: RAI IVS1 A4364G, ERCC1 Asn118Asn and ASE-1 G-21A, of which haplotype carriers are defined as the homozygous carriers of RAI IVS1 A4364GA , ERCC1 Asn 118Asn ${ }^{\mathrm{T}}$ and ASE-1 G$21 A^{G}$.

RAI encodes a specific inhibitor of the RelA subunit (p65) in the NF- $\kappa$ B transcription factor [6], which participates in inflammatory responses [7] and as an regulator of apoptosis [8]. The regulator function of $N F-\kappa B$, as an inhibitor or an activator of apoptosis, may depend on the ratio between the two NF-кB subunits RelA and c-Rel: An overexpression of RelA inhibits apoptosis, while an overexpression of c-Rel enhances apoptosis [8]. Inhibition of RAI synthesis has been shown to inhibit apoptosis [9]. In human colorectal adenomas and adenocarcinomas a constitutively increased expression of RelA/NF- $\mathrm{B}$ protein have been observed $[10,11]$. The increase was not detected in healthy colorectal mucosa [10]. It was recently shown that RAI expression is increased in both adenoma and adenocarcinoma tissue compared to tissue from normal colonic mucosa in the same person [12] indicating that high RAI expression occurs very early in the malignant transformation. However, contradictory results have been published as to whether the increased expression levels inhibit or promote apoptosis [9,13]. The polymorphisms in ERCC1 and in particular RAI are strongly associated with risk of basal cell carcinoma $[14,15]$.

ERCC1 encodes a subunit of the nucleotide excision repair (NER) complex, which is required for the incision step of NER [16]. For colorectal and lung cancer patients the mRNA levels and the expression of the ERCC1 protein are associated with the response to platinum-based chemotherapeutic drugs with direct impact on cancer patient survival. The level of response may be related to the ERCC1 Asn118Asn polymorphism [17-19], and the ERCC1 C8092A polymorphism as well, for lung cancer patients [20]. These epidemiological results are not entirely con- sistent, but they may indicate that the polymorphism predicts DNA repair capacity.

ASE-1 encodes a nucleolar protein, and is positioned in an anti-sense orientation to and overlaps with the gene for ERCC1. It is possibly involved with the RNA polymerase I transcription complex [21]. The exact role of ASE-1 and whether the overlapping between ERCC1 and ASE-1 gene has biological relevance are unknown.

In studies of Caucasians, the haplotype encompassing the three SNPs: ERCC1 Asn118Asn, ASE-1 G-21A and RAI IVS1 A4364G was strongly associated to risk of post-menopausal breast cancer [2] and lung cancer [3] among women less than 55 years of age when diagnosed with their first cancer. Female homozygous carriers of the haplotype were at a 7.02-fold (CI: 1.88-26.18) higher risk of lung cancer compared to female non-carriers of the homozygous haplotype, while the haplotype was associated to risk of breast cancer with an RR of 9.50 (CI: 2.2140.79 ) among female homozygous carriers of the haplotype, compared to women not carrying the homozygous haplotype. An association was not detected in the older age groups (55-60 years and $>60$ years when diagnosed with breast cancer) [2].

The mechanisms underlying the possible association between alcohol consumption and tobacco smoking and risk of colorectal cancer are unknown. Smoking has consistently been associated with increased risk for adenomas/polyps in colon and rectum [22]. Following tobacco smoking and intake of alcohol, DNA adducts are formed by metabolites of the carcinogens polycyclic aromatic hydrocarbons, aromatic amines, nitrosamines, and ethanol $[23,24]$. The adducts are not only located in airway tissue or the upper gastrointestinal tract, but are also found in e.g. white blood cells, bladder and cervical tissue [2527], indicating that systemic circulation of the carcinogens takes place. Thus, DNA lesions following tobacco smoking and alcohol consumption combined with a low DNA repair capacity or deficiency of triggering apoptosis in colonocytes may possibly lead to malignant transformation of the cells.

To our knowledge only two studies have been reported on gene-environment interactions with the predefined haplotype: A Norwegian case-control study on colorectal adenomas and adenocarcinomas [5] and our prospective case-cohort study on lung cancer [4]. No interaction was observed between the haplotype and cigarette smoking and intake of alcohol, respectively, in relation to risk of colorectal adenomas or adenocarcinomas [5]. In the lung cancer study, a stronger adverse association between smoking and risk of lung cancer were observed among women with a high smoking intensity (> $20 \mathrm{~g}$ tobacco/ 
day) carrying the homozygous high risk haplotype [4], than among female non-carriers of the homozygous haplotype with the same smoking intensity. An interaction between alcohol consumption and the haplotype was also found: Male carriers of the haplotype had a higher risk of lung cancer, whereas no association was found among men who were not carrying the homozygous haplotype.

In the present study, we hypothesized that female homozygous carriers of the previously identified haplotype have higher risk of colorectal cancer compared to individuals not carrying the homozygous haplotype, [5]. We expect that the haplotype or individual SNPs are linked to a biologically effective polymorphism. $R A I$ is an obvious candidate gene, since it has been shown to be required for induction of apoptosis [28], possibly through interaction with the $p 53$ gene [13]. Furthermore, we hypothesized the haplotype to interact with environmental factors such as smoking and alcohol consumption, in relation to risk of colorectal cancer as previously observed for lung cancer.

\section{Methods}

In 1993-1997, a total of 160,725 individuals were invited to participate in the Danish prospective "Diet, Cancer and Health" (DCH) study, the inclusion criteria being age 5064 years, born in Denmark and with no prior cancer diagnosis at the time of inclusion. In total, 57,053 participants accepted the invitation and were enrolled in the cohort [28]. At enrolment detailed information on diet, smoking habits, lifestyle, weight, height, reproduction, medical treatment, and other socio-economic characteristics and environmental exposures were collected. Moreover, blood, urine, fat tissue and other biological material was sampled and stored at $-150^{\circ} \mathrm{C}$. All participants gave informed consent. DCH and the present sub-study were approved by the Regional Ethical Committees on Human Studies in Copenhagen and Aarhus and by the Danish Data Protection Agency. Among the cohort members included in this study, 405 incident cases of colorectal cancer were identified, 184 women and 221 men, in the files of the nationwide Danish Cancer Registry [29], diagnosed between 1994 and 2003. Within the cohort we defined a sub-cohort consisting of 368 women and 442 men who were randomly selected. Cases and sub-cohort were matched on gender. Blood samples were available for 397 cases and 800 members of the sub-cohort. Information on smoking habits and alcohol consumption were available for all participants in the present study. Characteristics of the cases and the sub-cohort are shown in Table 1.

DNA was isolated from frozen blood samples as described [30]. All genotypes were determined by endpoint reading on a Sequence Detection System ABI 7500 (Applied Bio-
Table I: Characteristics of the study population nested within the Danish cohort Diet, Cancer and Health.

\begin{tabular}{lcc}
\hline & Cases & Sub-cohort \\
\hline $\begin{array}{l}\text { Totala } \\
\text { Gender }\end{array}$ & $405(100)$ & $810(100)$ \\
Men & & \\
Women & $221(55)$ & $442(54)$ \\
Age at inclusion ${ }^{\mathrm{b}}$ & $184(45)$ & $368(46)$ \\
Age at diagnosis & $58(5 \mathrm{I}-64)$ & $56(50-63)$ \\
Alcohol intake, g/dayb & $62(54-70)$ & - \\
Total & & \\
Men & $13(1-69)$ & $12(1-63)$ \\
Women & $23(2-88)$ & $19(1-77)$ \\
Smoking status at inclusion ${ }^{\mathrm{a}}$ & $8(0-4 \mathrm{I})$ & $8(1-39)$ \\
Never & & \\
Former & $123(30)$ & $272(33)$ \\
Present & $122(30)$ & $252(31)$ \\
Smoking intensity, g tobacco/day ${ }^{\mathrm{b}}$ & $160(40)$ & $286(36)$ \\
Total & $15(4-37)$ & $15(2-35)$ \\
Men & $19(4-4 \mathrm{I})$ & $18(2-40)$ \\
Women & $12(3-22)$ & $12(2-23)$ \\
Smoking duration, years ${ }^{\mathrm{b}}$ & & \\
Total & $34(8-47)$ & $32(6-46)$ \\
Men & $34(8-48)$ & $32(8-48)$ \\
Women & $34(7-45)$ & $32(4-44)$ \\
\hline & &
\end{tabular}

a) Number (\%)

b) Median (5-95\% percentiles)

systems, Nærum, Denmark). The case-control status of the samples was blinded when analysing the DNA in the laboratory. Controls with known genotypes were included in each run and repeated genotyping of a random $10 \%$ subset yielded $100 \%$ identical genotypes.

Primers and probes for ERCC1 Asn118Asn (C/T) (rs \#3177700), ASE-1 G-21A (rs \#967591) and RAI A4364G (rs \#1970764) genotyping were as previously described [4,31].

Five $\mu \mathrm{L}$ reactions contained $100 \mathrm{nM}$ of each probe, 900 nM primers, 20-50 ng DNA and 1x Mastermix (Applied Biosystems, Nærum, Denmark). The polymorphisms were analysed for 40 cycles at $15 \mathrm{~s}$ at $94^{\circ} \mathrm{C}$, and an elongation step performed at $62^{\circ} \mathrm{C}(A S E-1), 62^{\circ} \mathrm{C}(R A I)$ and $63^{\circ} \mathrm{C}(E R C C 1)$ for 60 s.

The ERCC1 Asn118Asn genotyping was unsuccessful for 7 samples, whereas 2 were unsuccessful for ASE-1 G-21A genotyping, and 8 for RAI A4364G.

The data were sampled according to the case-cohort design and the unweighted case-cohort approach was used for analysis [32]. Incidence rate ratios (IRR) for colorectal cancer were estimated by the Cox proportional hazards model. All the analyses were stratified according to gender. Age was the underlying time axis. The analyses 
were corrected for delayed entry, thereby considering risk only from the person's age at enrolment in the cohort. We calculated two-sided 95\% confidence intervals (CI) and pvalues based on robust estimates of the variance-covariance matrix [33] and Wald's test of the Cox regression parameter, that is, on the log rate ratio scale.

The genotype distributions of the polymorphisms were checked among the sub-cohort to verify Hardy-Weinberg equilibrium. We estimated IRR for the heterozygous and the homozygous variant, respectively, compared with the homozygous wild type. These estimates were supplemented with a trend test where the IRR is assumed to increase/decrease log-linearly with the number of variant type alleles. We analyzed data separately for each gender and each of two age groups ( $\leq 60$ years and $>60$ years) and separately according to topology of the cancer (colon or rectum, right- or left-sided segment of colon).

Smoking intensity was calculated as the average of the self-reported smoking intensity for the age intervals 2029, 30-39, 40-49 and 50-59 years and reported smoking status, smoking duration and alcohol consumption refer to the time of enrolment into the cohort study. Former smokers were defined as the participants who have been smoking regularly, at least one cigarette, pipe, cheroot or cigar daily, for at least one year, but who were not smoking daily at the time of enrolment. Smoking intensity for former smokers were calculated as the smoking intensity for each age intervals subtracted the periods of not smoking.

For each of the continuous variables, the hypothesis of a linear association was evaluated using a linear spline with three boundaries, placed at the quartiles among cases, as covariates in the Cox model [34]. The linearity was evaluated graphically and by a numerical test using the likelihood ratio test statistic to compare the model assuming linearity with the linear spline model. All variables were found linearly associated with colorectal cancer.

Interactions between the genotypes and each of the environmental factors, smoking status, smoking duration, average smoking intensity and alcohol consumption, were analysed by estimating separate associations for each genotype (homozygous wild type, heterozygous type and homozygous variant type). We tested the null hypothesis that the effect of the environmental factor was the same for the three genotypes. All models on gene-environment interactions were adjusted for smoking status (ever/never) or alcohol intake (yes/no). Thus, the effect of smoking intensity and duration were estimated among smokers only, and the effect of alcohol intake was estimated among alcohol consumers only. In the Cox regression model, we stratified according to gender allowing separate underlying risk for men and women, respectively. Hence, adjustment for HRT use in the analyses affects the risk estimates for women only. We used SAS PROC PHREG (version 8.2) for the estimations.

An $80 \%$ power required IRRs between 1.3 and 1.4 per variant allele for the three polymorphisms in the analyses of a linear trend at a significance level of 5\%. A similar power required an IRR of 1.5 for the homozygous haplotype versus non-carriers of the homozygous haplotype. The power calculations were made on the basis of the allele frequencies and number of participants in the present study.

\section{Results}

Fifty-two percent of the cases were diagnosed with colon cancer, $45 \%$ with rectal cancer, and in 3\% of the cases the topography was not specified. Among cases, 96\% had a diagnosis of adenocarcinomas, $2 \%$ of carcinoid tumor and $2 \%$ of various other histological subtypes. The distribution of cancer location was comparable for men and women, data not shown. The median consumption of alcohol was comparable between cases and sub-cohort members (Table 1). The proportion of present smokers was higher among cases than among members of the subcohort. Smoking intensity was comparable between cases and members of the sub-cohort, while smoking duration among male and female cases, respectively, were longer than among members of the sub-cohort. Smoking intensity was substantially higher among men than among women. In addition, the alcohol consumption was higher among men than women (Table 1).

The genotype distributions were in Hardy-Weinberg equilibrium among the sub-cohort members for all three polymorphisms both before and after gender separation, results not shown. The allelic frequencies of the variant allele for ASE-1 G-21A (0.17), RAI IVS1 A4364G (0.19), and ERCC1 Asn118Asn (0.36) were similar to the frequencies of alleles found in previous studies of Caucasians [3,5,31]. The genotype distributions were comparable between cases and members of the subcohort, results not shown.

Overall, there were no statistically significant associations between the three polymorphisms and risk of colorectal cancer, either among men or women (Table 2). The association between the haplotype and risk of colorectal cancer did not differ statistically significant between men and women $(P=0.16)$. However, women carrying the high risk haplotype seemed to be at higher risk of colorectal cancer with an IRR of 1.35 (0.84-2.16), compared with female non-carriers of the homozygous haplotype. The association between the three polymorphisms, ASE-1 G21A, RAI IVS1 A4364G and ERCC1 Asn118Asn and color- 
Table 2: Association between ERCCI Asn I I8Asn, ASE-IG-2 IA, RAI IVS I A4364G polymorphism and haplotype and risk of colorectal cancer

\begin{tabular}{|c|c|c|c|c|c|c|c|c|c|}
\hline & & Men & & & & Vomen & & & \\
\hline & SNP & $N_{\text {cases/sub-cohort }}$ & IRRab & $\mathrm{Cl}(95 \%)^{\mathrm{c}}$ & $\mathrm{Pd}$ & $\mathrm{N}_{\text {cases/sub-cohort }}$ & $I^{R R}{ }^{a b}$ & $\mathrm{Cl}(95 \%)^{\mathrm{c}}$ & Pd \\
\hline ERCCI Asn I I8Asn & TT & $84 / 177$ & $\mathrm{le}$ & $*$ & & $84 / 156$ & le & $*$ & \\
\hline & CT & $100 / 193$ & 1.04 & $0.72-1.50$ & 0.66 & $66 / 156$ & 0.78 & $0.51-1.19$ & 0.48 \\
\hline & $\mathrm{CC}$ & $34 / 61$ & 1.13 & $0.66-1.94$ & & $27 / 52$ & 0.90 & $0.50-1.63$ & \\
\hline & missing & $3 / 11$ & & & & $7 / 4$ & & & \\
\hline ASE-I G-2IA & GG & $152 / 299$ & le & $*$ & & $124 / 248$ & le & $*$ & \\
\hline & $A G$ & $60 / 124$ & 0.94 & $0.64-1.38$ & 0.73 & $45 / 106$ & 0.85 & $0.55-1.32$ & 0.96 \\
\hline & $\mathrm{AA}$ & $7 / 10$ & 2.11 & $0.7 I-6.2 I$ & & $9 / 11$ & 1.58 & $0.60-4.18$ & \\
\hline & missing & $2 / 9$ & & & & $6 / 3$ & & & \\
\hline RAI IVSI A4364G & $\mathrm{AA}$ & $156 / 280$ & $\mathrm{le}$ & $*$ & & $107 / 230$ & le & $*$ & \\
\hline & AG & $56 / 138$ & 0.69 & $0.47-1.03$ & 0.13 & $61 / 124$ & 1.17 & $0.77-1.80$ & 0.20 \\
\hline & GG & $6 / 13$ & 0.89 & $0.31-2.57$ & & $8 / 10$ & 1.95 & $0.7 I-5.33$ & \\
\hline & missing & $3 / 11$ & & & & & & & \\
\hline High risk haplotype & No & $165 / 319$ & $\mathrm{le}$ & $*$ & & $125 / 280$ & $\mathrm{le}$ & * & \\
\hline & $Y_{e s}^{f}$ & $53 / 110$ & 1.01 & $0.68-|.5|$ & & $51 / 82$ & 1.35 & $0.84-2.16$ & \\
\hline & missing & $3 / 13$ & & & & $8 / 6$ & & & \\
\hline
\end{tabular}

a) IRR: incidence rate ratio

b) Adjusted for average smoking intensity, intake of alcohol, fruits/vegetables, fish/poultry, red and processed meat, dietary fibres, BMI and hormone replacement therapy.

c) $\mathrm{Cl}: 95 \%$ confidence interval

d) P: trend test

e) The genotype serves as reference category

f) Homozygous carriers of the haplotype compared to the rest. Homozygous carrier of the previously identified haplotype consisting of ERCCI Asn I I8Asn ${ }^{T T}$, ASE-I G-2IAGG and RAI IVSI A4364GAA

ectal cancer was not statistically significant different (all P $>0.25$ ) between genders.

There were no significant effects of the three polymorphisms and the haplotype in relation to risk of colorectal cancer in the topological sub-groups (left-or right sided segment of colon or rectal, results not shown), and no statistically significant effects were observed of the three polymorphisms and the high risk haplotype in relation to risk of colorectal cancer in either of the two age groups ( $\leq$ 60 years and $>60$ years), results not shown. Thus, further statistical analysis includes all cases regardless of location of the cancer and age when diagnosed with colorectal cancer. The effect of smoking status at enrolment, smoking duration, average smoking intensity and intake of alcohol on colorectal cancer risk did not differ between genders, results not shown. However, since we previously have found gender-specific gene-environment interactions in the recent lung cancer study, the interaction studies on the polymorphisms and the haplotype were stratified by gender.

There were no statistically significant interactions between the haplotype and smoking intensity or alcohol consumption (Table 3), or between the ASE-1 G-21A, RAI IVS1 A4364G and ERCC1 Asn118Asn polymorphisms, respectively, and smoking intensity or alcohol consumption (see Additional file 1), in relation to risk of colorectal cancer. Yet, there was a tendency that smoking intensity was a risk factor for colorectal cancer among homozygous carriers of the variant ASE-1 G-21A allele especially among men. No effect was observed among carriers of the wild type. We observed no statistically significant interactions between the genotypes and smoking status and smoking duration at enrolment associated to risk of colorectal cancer, results not shown.

\section{Discussion}

Overall, we observed no association between the previously identified haplotype and the RAI IVS1 A4364G, ASE-1 G-21A and ERCC1 Asn118Asn polymorphisms and risk of colorectal cancer. We did not find any interactions between the genotypes or the haplotype and the lifestyle exposures smoking intensity or alcohol consumption in relation to risk of colorectal cancer.

The present study is population based. Selection bias is unlikely because the sub-cohort used was selected as a stratified random sample from the same cohort that gave rise to the included colorectal cancer cases. The inclusion of 405 cases and a comparison group of 810 individuals provided a relatively high statistical power. For all participants, information on smoking habits and alcohol consumption was obtained at enrolment before a cancer 
Table 3: Gene-environment interaction stratified by gender. Haplotype-specific effects of average smoking intensity and consumption of alcohol on the risk of colorectal cancer

\begin{tabular}{|c|c|c|c|c|c|c|c|c|c|}
\hline \multirow[t]{2}{*}{ Haplotype } & \multicolumn{2}{|r|}{ Men } & \multicolumn{6}{|c|}{ Women } & \multirow[b]{2}{*}{$\mathrm{Pd}$} \\
\hline & Carrier $^{\mathrm{a}}$ & $\mathrm{N}_{\text {cases/sub-cohort }}$ & $I_{R} R^{b}$ & $\mathrm{Cl}(95 \%)^{\mathrm{c}}$ & $P d$ & $\mathrm{~N}_{\text {cases/sub-cohort }}$ & $I_{R} R^{b}$ & $\mathrm{Cl}(95 \%)^{\mathrm{c}}$ & \\
\hline \multirow[t]{3}{*}{ Smoking intensitye (per $10 \mathrm{~g}$ tobacco/day) } & No & $130 / 232$ & 0.93 & $0.76-1.13$ & 0.26 & $62 / 149$ & 1.58 & $0.99-2.50$ & 0.42 \\
\hline & Yes & $45 / 74$ & 1.14 & $0.79-1.63$ & & $31 / 52$ & 1.23 & $0.64-2.38$ & \\
\hline & missing & $3 / 8$ & & & & $4 / 4$ & & & \\
\hline \multirow[t]{3}{*}{ Alcohol intakef (per 10 g/day) } & No & $164 / 313$ & 1.04 & $0.97-1.12$ & 0.15 & $121 / 276$ & 1.15 & $0.98-1.36$ & 0.17 \\
\hline & Yes & $51 / 104$ & 1.20 & $1.00-1.43$ & & $47 / 80$ & 0.87 & $0.61-1.25$ & \\
\hline & missing & $3 / 13$ & & & & $7 / 6$ & & & \\
\hline
\end{tabular}

a) Homozygous carriers of the haplotype compared to the rest. Homozygous carrier of the previously identified haplotype consisting of ERCCI Asn I I8Asn TT, ASE-I G-2IAGG and RAI IVSI A4364GAA

b) IRR: incidence rate ratio

c) $\mathrm{Cl}: 95 \%$ confidence interval

d) P: test for interaction

e) Risk estimates for ever smokers only. Adjusted for smoking status (present/former/never), intake of alcohol, fruits/vegetables, fish/poultry, red and processed meat, dietary fibres, BMI and hormone replacement therapy.

f) Risk estimates for alcohol consumers only. Adjusted for average smoking intensity, fruits/vegetables, fish/poultry, red and processed meat, dietary fibres, BMI and hormone replacement therapy

diagnosis, which minimizes the risk for differential misclassification of these exposures between the cases and the comparison group.

In previous studies the RAI IVS1 A4364G polymorphism has been associated with a lower risk of basal cell carcinoma, lung cancer and post-menopausal breast cancer $[2,3,15]$ among homozygous carriers of the variant allele. The strongest association with risk of breast cancer or basal cell carcinoma was observed among the youngest individuals $[2,14,15]$. The RAI IVS1 A4364G polymorphism was not associated with risk of testicular cancer [31]. Our results on the ASE-1 G-21A and ERCC1 Asn118Asn polymorphisms and risk of colorectal cancer are comparable to other cancer studies, where no associations have been observed between the two polymorphisms and risk of basal cell carcinoma, post-menopausal breast cancer and testicular cancer $[2,31,35]$.

A tendency of higher risk for colorectal carcinoma, with an OR of 2.19 (CI: 0.95-5.04), was observed among Norwegian women carrying the homozygous haplotype compared to women not carrying the homozygous haplotype [5]. The results of the present study are comparable, with an IRR of 1.35 (CI: 0.84-2.16). However, in neither of the studies statistically significant gender-specific gene effects of the haplotype were observed. Previous studies on breast and lung cancer found a strong age dependent and gender-specific effect of the haplotype on risk of cancer $[2,3]$. A possible reason for not detecting any association between the haplotype and risk of colorectal cancer in the present study, may thus be due to the relatively high age among cases (median 62 years) when diagnosed with colorectal cancer. We were not able to estimate a risk association for the age-group younger than 55 years due to low number of cases ( 8 cases carrying the homozygous haplotype). When data was stratified by age with members of the youngest age group being less or equal to 60 years when diagnosed with colorectal cancer, still no statistically significant associations between the haplotype and risk of colorectal cancer were detected, results not shown.

Smoking intensity increased the risk of colorectal cancer among homozygous carriers of the variant ASE-1 G-21A polymorphism. The effect may very possibly be a chance finding due to low numbers of cases and members of the sub-cohort. Thus, no convincing statistical significant interactions were observed between the three genotypes and alcohol consumption or the smoking variables related with risk of colorectal cancer.

We observed no interaction between the haplotype and smoking intensity on risk of colorectal cancer. Our previous study on risk of lung cancer found a borderline significant interaction $(\mathrm{P}=0.06)$ between high smoking intensity (>20 g tobacco/day) and the haplotype related with risk of lung cancer, with a 2.03-fold increased risk of lung cancer per additional $5 \mathrm{~g}$ tobacco/day among women carrying the haplotype, while no association were observed among female non-carriers of the haplotype with a similar smoking intensity [4]. Among women with a lower smoking intensity ( $\leq 20 \mathrm{~g}$ tobacco/day) no effect was observed of smoking intensity on risk of lung cancer among carriers or non-carriers of the homozygous haplotype. In the present study it was not possible to access the effect of a high smoking intensity among women due to a lower smoking intensity among female cases. The findings in the present study is thus similar to the above mentioned results in the lung cancer study [4] for women with a comparable low smoking intensity. 
Alcohol consumption did not have a significantly different effect on carriers and non-carriers of the homozygous haplotype $(\mathrm{P}>0.13)$ among men and women, respectively, in relation to risk of colorectal cancer. However, we detected an adverse effect of alcohol among male carriers of the homozygous haplotype, with an IRR of 1.20 (CI: 1.00-1.43), per $10 \mathrm{~g}$ alcohol intake per day. In the Norwegian study of colorectal cancer, the alcohol consumption was lower among cases than in the present study, and approximately $40 \%$ of the cases were abstainers [36]. No interaction between the high risk haplotype and alcohol intake on risk of colorectal adenomas and carcinomas was observed [5]. In our recent lung cancer study, alcohol consumption was associated with a 1.40-fold (CI: 1.13-1.74) increased risk of lung cancer per $10 \mathrm{~g}$ alcohol intake per day among male carriers of the homozygous haplotype [4]. The effect of alcohol was significantly different between carriers and non-carriers of the homozygous haplotype $(P=0.003)$. Although a similar gene-environment interaction seems not to exist for colorectal cancer, we cannot exclude a weak tendency of interaction between alcohol consumption and the homozygous high risk haplotype among men.

\section{Conclusion}

Overall, the ASE-1 G-21A, RAI IVS1 A4364G and ERCC1 Asn118Asn polymorphisms and the previously identified haplotype were not associated with risk of colorectal cancer. No statistically significant interactions were observed between the high risk haplotype, the three polymorphisms and smoking intensity and alcohol consumption, respectively, in relation to the risk of colorectal cancer.

\section{Competing interests}

The author(s) declare that they have no competing interests.

\section{Authors' contributions}

RDH isolated the DNA for analysis, genotyped the DNA samples, made the data analysis and drafted the manuscript

MS and ORN contributed with strategies for data analysis

AT and KO brought the idea of the "Diet, Cancer and Health" study and organized it

HW and UV contributed with idea and design of the present study

All authors contributed to interpretation of the results and to the final manuscript.

\section{Additional material}

\section{Additional File 1}

Table 4 Gene-environment interaction stratified by gender. ERCC1 Asn118Asn, ASE-1 G-21A and RAI IVS1 A4364G genotype-specific effects of average smoking intensity and consumption of alcohol on the risk of colorectal cancer. The table presents the genotypic distribution of the three polymorphisms in the ERCC1, ASE-1 and RAI genes for both cases and controls, and the incidence rate ratios of colorectal cancer risk associated with the three polymorphisms.

Click here for file

[http://www.biomedcentral.com/content/supplementary/14712407-8-54-S1.pdf]

\section{Acknowledgements}

We thank Anne-Karin Jensen, Lourdes M. Pedersen and Yonit M. Bertelsen for excellent technical assistance. This study was supported by Danish Research Council (Grant number 2052-03-0016) and a scholarship from the Danish Graduate School in Public Health Science and from the Faculty of Medicine at University of Copenhagen.

\section{References}

I. Goode EL, Ulrich CM, Potter JD: Polymorphisms in DNA repair genes and associations with cancer risk. Cancer Epidemiol Biomarkers Prev 2002, I I:1513-1530.

2. Nexo BA, Vogel U, Olsen A, Ketelsen T, Bukowy Z, Thomsen BL, Wallin $\mathrm{H}$, Overvad $\mathrm{K}$, Tjonneland A: A specific haplotype of single nucleotide polymorphisms on chromosome I9q13.2-3 encompassing the gene RAl is indicative of post-menopausal breast cancer before age 55. Carcinogenesis 2003, 24:899-904.

3. Vogel U, Laros I, Jacobsen NR, Thomsen BL, Bak H, Olsen A, Bukowy Z, Wallin H, Overvad K, Tjonneland A, Nexo BA, Raaschou-Nielsen O: Two regions in chromosome $19 \mathrm{q} 13.2-3$ are associated with risk of lung cancer. Mutat Res 2004, 546:65-74.

4. Vogel U, Sorensen M, Hansen RD, Tjonneland A, Overvad K, Wallin $H$, Nexo BA, Raaschou-Nielsen O: Gene-environment interactions between smoking and a haplotype of RAI, ASE-I and ERCCI polymorphisms among women in relation to risk of lung cancer in a population-based study. Cancer Lett 2007, 247:159-165.

5. Skjelbred CF, Sabo M, Nexo BA, Wallin H, Hansteen IL, Vogel U, Kure EH: Effects of polymorphisms in ERCCI, ASE-I and RAI on the risk of colorectal carcinomas and adenomas: $A$ case control study. BMC Cancer 2006, 6: 175 .

6. Yang JP, Hori M, Sanda T, Okamoto T: Identification of a novel inhibitor of nuclear factor-kappaB, RelA-associated inhibitor. J Biol Chem 1999, 274: I5662-15670.

7. Greten FR, Eckmann L, Greten TF, Park JM, Li ZW, Egan LJ, Kagnoff $M F, K a r i n ~ M$ : IKKbeta links inflammation and tumorigenesis in a mouse model of colitis-associated cancer. Cell 2004, I I 8:285-296.

8. Chen X, Kandasamy K, Srivastava RK: Differential roles of RelA (p65) and c-Rel subunits of nuclear factor kappa $B$ in tumor necrosis factor-related apoptosis-inducing ligand signaling. Cancer Res 2003, 63:1059-1066.

9. Laska MJ, Strandbygard D, Kjeldgaard A, Mains M, Corydon TJ, Memon AA, Sorensen BS, Vogel U, Jensen UB, Nexo BA: Expression of the RAl gene is conducive to apoptosis: studies of induction and interference. Exp Cell Res 2007, 3 I 3:26I I-262I.

10. Yu HG, Yu LL, Yang Y, Luo HS, Yu JP, Meier JJ, Schrader H, Bastian A, Schmidt WE, Schmitz F: Increased expression of RelA/nuclear factor-kappa B protein correlates with colorectal tumorigenesis. Oncology 2003, 65:37-45.

II. Lind DS, Hochwald SN, Malaty J, Rekkas S, Hebig P, Mishra G, Moldawer LL, Copeland EM III, Mackay S: Nuclear factor-kappa B is upregulated in colorectal cancer. Surgery 200I, 130:363-369. 
12. Saebo M, Skjelbred CF, Nexo BA, Wallin H, Hansteen IL, Vogel U, Kure EH: Increased mRNA expression levels of ERCCI, OGGI and RAI in colorectal adenomas and carcinomas. BMC Cancer 2006, 6:208.

13. Bergamaschi D, Samuels Y, O'Neil NJ, Trigiante G, Crook T, Hsieh JK, O'Connor DJ, Zhong S, Campargue I, Tomlinson ML, Kuwabara PE, Lu X: iASPP oncoprotein is a key inhibitor of p53 conserved from worm to human. Nat Genet 2003, 33:162-167.

14. Rockenbauer E, Bendixen MH, Bukowy Z, Yin J, Jacobsen NR, Hedayati M, Vogel U, Grossman L, Bolund L, Nexo BA: Association of chromosome $19 \mathrm{q} / 3.2-3$ haplotypes with basal cell carcinoma: tentative delineation of an involved region using data for single nucleotide polymorphisms in two cohorts. Carcinogenesis 2002, 23: I |49-I I53.

15. Yin J, Rockenbauer E, Hedayati M, Jacobsen NR, Vogel U, Grossman L, Bolund L, Nexo BA: Multiple single nucleotide polymorphisms on human chromosome 19q 13.2-3 associate with risk of Basal cell carcinoma. Cancer Epidemiol Biomarkers Prev 2002. II:I449-1453.

16. de Laat WL, Jaspers NG, Hoeijmakers JH: Molecular mechanism of nucleotide excision repair. Genes Dev 1999, 13:768-785.

17. Viguier J, Boige V, Miquel C, Pocard M, Giraudeau B, Sabourin JC, Ducreux M, Sarasin A, Praz F: ERCCI codon II 8 polymorphism is a predictive factor for the tumor response to oxaliplatin/5fluorouracil combination chemotherapy in patients with advanced colorectal cancer. Clin Cancer Res 2005, II:62 I2-62 I7.

18. Park DJ, Zhang W, Stoehlmacher J, Tsao-Wei D, Groshen S, Gil J, Yun J, Sones E, Mallik N, Lenz HJ: ERCCI gene polymorphism as a predictor for clinical outcome in advanced colorectal cancer patients treated with platinum-based chemotherapy. Clin Adv Hematol Oncol 2003, I: 162-166.

19. Ryu JS, Hong YC, Han HS, Lee JE, Kim S, Park YM, Kim YC, Hwang TS: Association between polymorphisms of ERCCI and XPD and survival in non-small-cell lung cancer patients treated with cisplatin combination chemotherapy. Lung Cancer 2004 44:3||-3|6.

20. Zhou W, Gurubhagavatula S, Liu G, Park S, Neuberg DS, Wain JC Lynch TJ, Su L, Christiani DC: Excision repair cross-complementation group I polymorphism predicts overall survival in advanced non-small cell lung cancer patients treated with platinum-based chemotherapy. Clin Cancer Res 2004, 10:4939-4943

21. Whitehead CM, Winkfein RJ, Fritzler MJ, Rattner JB: ASE-I: a novel protein of the fibrillar centres of the nucleolus and nucleolus organizer region of mitotic chromosomes. Chromosoma 1997, 106:493-502.

22. Schottenfeld D, Winawer SJ: Cancers of the large intestine. In Cancer Epidemiology and Prevention Volume 39. second edition. Edited by: Schottenfeld D and J.F.Jr. F. New York, Oxford University Press; 1996:813-840.

23. Hecht SS, Hoffmann D: Tobacco-specific nitrosamines, an important group of carcinogens in tobacco and tobacco smoke. Carcinogenesis 1988, 9:875-884.

24. Brooks PJ, Theruvathu JA: DNA adducts from acetaldehyde: implications for alcohol-related carcinogenesis. Alcohol 2005 35:187-193.

25. Melikian AA, Sun P, Prokopczyk B, El-Bayoumy K, Hoffmann D, Wang $X$, Waggoner S: Identification of benzo[a]pyrene metabolites in cervical mucus and DNA adducts in cervical tissues in humans by gas chromatography-mass spectrometry. Cancer Lett 1999, 146:127-134.

26. Benhamou S, Laplanche A, Guillonneau B, Mejean A, Desgrandchamps $F$, Schrameck C, Degieux V, Perin F: DNA adducts in normal bladder tissue and bladder cancer risk. Mutagenesis 2003, 18:445-448

27. Fang JL, Vaca CE: Detection of DNA adducts of acetaldehyde in peripheral white blood cells of alcohol abusers. Carcinogenesis 1997, 1 8:627-632.

28. Tjonneland A, Gronbaek M, Stripp C, Overvad K: Wine intake and diet in a random sample of 48763 Danish men and women. Am J Clin Nutr 1999, 69:49-54.

29. Storm HH, Michelsen EV, Clemmensen IH, Pihl J: The Danish Cancer Registry--history, content, quality and use. Dan Med Bull 1997, 44:535-539.
30. Miller SA, Dykes DD, Polesky HF: A simple salting out procedure for extracting DNA from human nucleated cells. Nucleic Acids Res 1988, 16:1215

31. Laska MJ, Nexo BA, Vistisen K, Poulsen HE, Loft S, Vogel U: Polymorphisms in RAl and in genes of nucleotide and base excision repair are not associated with risk of testicular cancer. Cancer Lett 2005, 225:245-25I.

32. Barlow WE, Ichikawa L, Rosner D, Izumi S: Analysis of case-cohort designs. J Clin Epidemiol 1999, 52: I I65- I I72.

33. Barlow WE: Robust variance estimation for the case-cohort design. Biometrics 1994, 50:1064-1072.

34. Greenland S: Dose-response and trend analysis in epidemiology: alternatives to categorical analysis. Epidemiology 1995, 6:356-365.

35. Vogel U, Olsen A, Wallin H, Overvad K, Tjonneland A, Nexo BA Effect of polymorphisms in XPD, RAI, ASE-I and ERCCI on the risk of basal cell carcinoma among Caucasians after age 50. Cancer Detect Prev 2005, 29:209-2I4.

36. Gondal G, Grotmol T, Hofstad B, Bretthauer M, Eide TJ, Hoff G: Lifestyle-related risk factors and chemoprevention for colorectal neoplasia: experience from the large-scale NORCCAP screening trial. Eur J Cancer Prev 2005, 14:373-379.

\section{Pre-publication history}

The pre-publication history for this paper can be accessed here:

http://www.biomedcentral.com/1471-2407/8/54/prepub
Publish with Bio Med Central and every scientist can read your work free of charge

"BioMed Central will be the most significant development for disseminating the results of biomedical research in our lifetime. "

Sir Paul Nurse, Cancer Research UK

Your research papers will be:

- available free of charge to the entire biomedical community

- peer reviewed and published immediately upon acceptance

- cited in PubMed and archived on PubMed Central

- yours - you keep the copyright

Submit your manuscript here:

http://www.biomedcentral.com/info/publishing_adv.asp 